Swarthmore College

Works

$4-1-2013$

\title{
The Temporal Doppler Effect: When The Future Feels Closer Than The Past
}

E. M. Caruso

L. Van Boven

Mark J. Chin , '12

Andrew Ward

Swarthmore College, award1@swarthmore.edu

Follow this and additional works at: https://works.swarthmore.edu/fac-psychology

Part of the Psychology Commons

Let us know how access to these works benefits you

\section{Recommended Citation}

E. M. Caruso; L. Van Boven; Mark J. Chin , '12; and Andrew Ward. (2013). "The Temporal Doppler Effect: When The Future Feels Closer Than The Past". Psychological Science. Volume 24, Issue 4. 530-536. DOI: $10.1177 / 0956797612458804$

https://works.swarthmore.edu/fac-psychology/195

This work is brought to you for free by Swarthmore College Libraries' Works. It has been accepted for inclusion in Psychology Faculty Works by an authorized administrator of Works. For more information, please contact myworks@swarthmore.edu. 
In press, Psychological Science.

The Temporal Doppler Effect:

When the Future Feels Closer than the Past

\author{
Eugene M. Caruso \\ University of Chicago \\ Leaf Van Boven \\ University of Colorado Boulder \\ Mark Chin \\ Swarthmore College \\ Andrew Ward \\ Swarthmore College
}

Address correspondence to:

Eugene M. Caruso

The University of Chicago

Booth School of Business

5807 South Woodlawn Avenue

Chicago, IL 60637

773-834-3847

ecaruso@chicagobooth.edu 


\begin{abstract}
People routinely remember events that have passed and imagine those that are yet to come. The past and the future are sometimes psychologically close (“just around the corner”) and other times psychologically distant ("ages away"). Four studies demonstrate a systematic asymmetry whereby future events are psychologically closer than past events of equivalent objective distance. When considering specific times (e.g., one year) or events (e.g., Valentine's Day), people consistently reported that the future was closer than the past. We suggest that this asymmetry arises because the subjective experience of movement through time (whereby future events approach and past events recede) is analogous to the physical experience of movement through space. Consistent with this hypothesis, experimentally reversing the metaphorical arrow of time (by having participants move backward through virtual space) completely eliminated the past-future asymmetry. We discuss how reducing psychological distance to the future may function to prepare people for upcoming action.
\end{abstract}

Keywords: psychological distance, time, tense, past and future 


\section{The Temporal Doppler Effect:}

\section{When the Future Feels Closer than the Past}

We conceive the future as flowing every moment nearer us, and the past as retiring. An equal distance, therefore, in the past and in the future, has not the same effect on the imagination; and that because we consider the one as continually encreasing, and the other as continually diminishing.

-David Hume (1739)

Time flies. Time marches on. Time flows like a river. Many metaphors capture elements of the self in time. The most common, perhaps, is the "arrow of time," which implies both movement and direction. People move from the past toward the future; events approach from the future and recede into the past. A common theme in such metaphors is that the descriptions of time are grounded in the sensory experiences of spatial movement. Here we reason that the experience of movement through time is analogous to the experience of movement through space.

We hypothesize that the spatial metaphor of events in time implies a fundamental asymmetry in the psychological distance of past and future events: Future events are psychologically closer to the present than past events of equivalent objective distance. Because, as Hume observed, "we conceive the future as flowing every moment nearer us, and the past as retiring," the distance between the self and future events diminishes whereas the distance between the self and past events increases. Just as diminishing spatial separation makes objects seem spatially closer and increasing spatial separation makes objects seem spatially more distant, diminishing temporal separation makes events seem temporally closer and increasing temporal separation makes events seem temporally more distant. The existence of this temporal 
asymmetry would have important implications for theories of psychological distance that assume temporal symmetry (e.g., Trope \& Liberman, 2010), and for theories of episodic memory that assume people remember the past in largely the same way that they imagine the future (e.g., Addis, Wong, \& Schacter, 2007).

\section{Movement through Space and Time}

People's experience with physical space is a fundamental metaphor that grounds mental representations of the self in the external world (Lakoff \& Johnson, 1980, 1999; Mandler, 1992; Williams \& Bargh, 2008). Because time and psychological distance are abstractions that are not directly experienced, people's mental representations of those abstractions are shaped by their direct experiences with spatial distances. Indeed, temporal units (e.g., one year) are often defined in terms of spatial units (e.g., the distance the earth travels in one revolution around the sun). Extending spatial distance as a metaphor for psychological distance, people's movement through

space metaphorically shapes their mental representations of movement through time (Boroditsky, 2000). People who have recently had direct experience with spatial movement (for example, by having flown on an airplane or ridden a train), compared with those who have not, are more likely to construe themselves as moving toward the future ("ego movement") rather than the future as moving toward the self ("time movement"; Boroditsky \& Ramscar, 2002).

The metaphorical mapping of spatial and temporal movement manifests in embodied expression (Casasanto \& Boroditsky, 2008). People tend to lean their bodies backward when thinking about the past whereas they lean their bodies forward when thinking about the future (Miles, Nind, \& Macrae, 2010). And illusory sensations of forward motion prompt thoughts about the future whereas illusory sensations of backward motion prompt thoughts about the past 
(Miles, Karpinska, Lumsden, \& Macrae, 2010). Backward and forward movement in physical space is thus intricately associated with backward and forward movement in time.

\section{The Temporal Doppler Effect}

We hypothesize that the associations of spatial and temporal movement influence the psychological distance of past and future points in time such that future time is psychologically closer than past time. Our hypothesis is derived from the proposition that patterns of perceived movement through space are associated with similar patterns of perceived movement through time. The fact that future events are associated with diminishing distance makes them psychologically closer than past events, which are associated with increasing distance. Accordingly, we predict that the temporal asymmetry in the psychological distance of past versus future events should emerge even when events are of a fixed or known objective distance. This temporal asymmetry would therefore be analogous to directional asymmetries in the visual and auditory perception of objects moving in space.

In visual perception, representational momentum is the tendency for implied movement of prior visual patterns to influence mental representations of current visual patterns. For instance, when observers watch a target moving from right to left across their visual field that then disappears, they subsequently remember the object as having travelled farther to the left than it actually did (Freyd \& Finke, 1984). People also perceive objects as closer than they actually are when they physically approach those objects in space (Lewin, 1935).

In auditory perception, the well-known Doppler effect (Doppler, 1942) is the tendency for noises that approach to be heard at a higher pitch than noises that recede, a phenomenon well demonstrated by the vocalizations of any child playing with toy airplanes, ambulances, or other moving vehicles. Because the distance between sound waves becomes successively smaller as 
the source approaches and successively larger as it recedes, the received pitch is relatively higher in front of the observer than behind the observer. ${ }^{1}$ As with representational momentum, people typically underestimate the distance of approaching sounds compared with receding sounds, even when the sounds are equally distant (Neuhoff, 2001; see also Guski, 1992).

The metaphorical grounding of temporal movement in spatial movement implies that the psychological distance of events in time is similar to the perception of objects' movement through space. Specifically, the psychological distance of events in time should mirror the representational momentum tendency in visual perception and the Doppler effect in auditory perception. Just as approaching objects in physical space seem closer than receding objects, approaching points in time may seem psychologically closer than receding times. In other words, people should exhibit a temporal Doppler effect in psychological distance.

\section{The Present Research}

We tested the temporal Doppler effect in four studies. We first asked participants to report the psychological distance to the same specific times (one month, Study 1a; one year, Study 1b) or events (Valentine's Day, Study 2) at objectively equal distances in either the past or the future. We predicted that people would report that future times were psychologically closer than past times of an equal objective distance. We then examined whether experimentally manipulating the (virtual) movement of the self through space would moderate the temporal Doppler effect, as implied by our analysis that metaphorical movement through space shapes psychological distance in time (Study 3).

\section{Study 1: One Month and One Year}

In Studies 1a and 1b, we sought to establish this basic temporal asymmetry in psychological distance across two generic time points. 


\section{Method}

Study 1a. Ninety-five undergraduates were asked either to think ahead to exactly one month from today (future condition) or to think back to exactly one month ago (past condition).

Study 1b. Ninety-eight commuters at a train station in Boston, MA, were asked either to think ahead to exactly one year from today (future condition) or to think back to exactly one year ago today (past condition). Participants in each study then reported the target day's psychological distance $(1=$ a really short time from now; $10=$ a really long time from now $)$.

\section{Results and Discussion}

Participants reported that a month in the future was closer than a month in the past, $t(93)$ $=2.52, p=.013, d=0.52$ and that a year in the future was closer than a year in the past, $t(96)=$ $2.19, p=.031, d=0.45$ (Table 1). These results provide evidence that times in the future are subjectively closer than objectively equidistant times in the past.

\section{Study 2: Valentine's Day}

We next sought to replicate the temporal Doppler effect with a specific event (at a specific time). Whereas participants in Studies $1 \mathrm{a}$ and $1 \mathrm{~b}$ reported psychological distance of generic times (one month, one year), we asked participants in Study 2 to report the psychological distance of a distinct event: Valentine's Day.

\section{Method}

Three hundred twenty-three participants from Amazon.com's Mechanical Turk service completed an online survey in exchange for $\$ 0.75$. Participants took the survey either 8 days before (future condition) or 7 days after (past condition) Valentine's Day. Because responses were collected over a 24-hour period, we administered the survey a day earlier in the future condition to ensure that the objective distance to Valentine's Day was at least as great (if not 
greater) in the future than in the past. After briefly describing what they planned to do [what they did] for Valentine's Day, participants reported psychological distance from the present by completing the phrase "It feels like Valentine's Day is..." (1 = an extremely short time from now; $7=$ an extremely long time from now).

\section{Results and Discussion}

Participants reported that Valentine's Day was psychologically closer one week before it happened than one week after it happened, $t(321)=4.56, p<.0001, d=0.51$ (Table 1). This result shows that a specific event in the future is psychologically closer than the same specific event in the past.

\section{Study 3: Virtual Movement}

Our central idea is that the psychological distance to the future and past is metaphorically grounded in movement of the self through physical space. The future is psychologically closer than the past because the future typically approaches the present whereas the past recedes from the present. This movement makes the future seem closer, just as an object approaching in space seems closer than an object receding in space. The embodiment of psychological distance in spatial metaphors implies that manipulations of (virtual) spatial embodiment should influence temporal psychological distance. If the spatially-grounded arrow of time was reversed - if people were made to approach the past and recede from the future - the temporal Doppler effect might be diminished, if not reversed.

We tested this prediction by manipulating the direction of participants' apparent physical movement, which we reasoned would influence people's orientation to the past and future. Some people had the (virtual) experience of moving forward in space, consistent with their natural orientation of thoughts, whereas others had the (virtual) experience of moving backward in 
space, reversing their natural orientation of thoughts. We predicted that people's virtual movement would moderate the temporal asymmetry in psychological distance such that backward movement would reduce, if not reverse, the tendency for future times to be psychologically closer than past times.

\section{Method}

Participants. Eighty undergraduates were randomly assigned (between-participants) to experience either forward or backward movement in virtual space and were either queried about a date that was three weeks in the past or one that was three weeks in the future.

Procedure. Participants were informed that they would view a scene using a virtual reality device and then answer questions about what they had observed. To focus participants on either the past or the future during the task, participants were further informed that "because we're running students at different points in the semester," it was necessary for the researchers to control for any differences associated with an individual's specific task participation date. Accordingly, after participants completed the virtual reality task, they were going to be asked to imagine their state "three weeks ago [from now]," and they were reminded of the relevant past or future calendar date.

Stimuli and apparatus. Participants experienced a virtual reality (VR) environment through means of a head-mounted display (for technical details, see Durgin \& Li, 2010). In the environment, participants found themselves on a paved two-lane road lined with trees, streetlights, and buildings on either side, along with a fountain at the head of the road (see Figure 1). ${ }^{2}$ The fountain provided auditory cues that diminished in volume with increasing virtual distance from the participant. Participants initially accelerated for $12 \mathrm{~s}$ to a top speed of approximately $24 \mathrm{mph}$ and ultimately decelerated for $12 \mathrm{~s}$ to a stop. 
Measures. Immediately after the virtual movement task, participants were asked, "How far in the past [future] does the date of 3 weeks ago [3 weeks from now] feel to you right now?" $(1=$ not far at all; 9 = extremely far $)$.

\section{Results and Discussion}

A 2 (spatial direction: forward, backward) $\times 2$ (temporal direction: future, past) ANOVA revealed only the predicted interaction, $F(1,76)=4.39, p=.040, \eta_{p}{ }^{2}=.06($ Table 2$){ }^{3}$ When moving forward, participants reported the future as closer than the past, $t(76)=2.18, p=$ $.032, d=.50$, consistent with the results of our previous studies and consistent with our suggestion that people's natural orientation is forward movement through time. When moving backward, in contrast, participants reported that the future was somewhat more psychologically distant than the past, although the effect was not significant, $t<1$. Further, planned contrasts revealed that the psychological distance of the future when moving forward was not different from the psychological distance of the past when moving backward, $t<1$, and the psychological distance of the future when moving backward was not different from the psychological distance of the past when moving forward, $t(76)=1.03, n s$.

The temporal Doppler effect was thus moderated when people moved virtually backward rather than forward through space. People tended to report that times were psychologically closer when their spatial movement corresponded with their metaphorical temporal direction. These findings provide additional support for the psychological interconnectedness of spatial and temporal orientation and demonstrate how the temporal asymmetry in psychological distance is shaped by people's perceived movement toward, rather than away from, the future.

\section{General Discussion}


Theoretical physicists and philosophers have remarked that time has no unique direction, such that the distinction between the past and future is merely "a stubbornly persistent illusion" (Einstein, 1955) and that "time's arrow is ... a gratuitous assumption" (Mehlberg, 1962, p. 104). Although the theoretical reality of time's direction is a matter of philosophical debate, the subjective reality is a matter of psychological consensus: People experience the distance between the future and the present as decreasing whereas they experience the distance between the past and the present as increasing. ${ }^{4}$ In four studies, we demonstrated one important consequence of experiential movement through time: a systematic tendency to experience the future as psychologically closer than the past. Our suggestion that this temporal Doppler effect is influenced by spatial metaphors is strengthened by the fact that the effect is eliminated by an experimental manipulation that (virtually) reverses the normal trajectory of forward spatial movement. The finding that patterns of perceived movement through space manifest in similar patterns of perceived movement through time is consistent with brain imaging data that implicates a common neural substrate underlying travel through space (i.e., navigation) and travel through time (i.e., memory and retrospection; Buckner \& Carroll, 2007), which reinforces the deep connection between the conceptual metaphors linking space travel and time travel.

\section{Additional Explanations}

The tendency demonstrated in our studies for the future to be psychologically closer than the past dovetails with several other psychological temporal asymmetries. One can ask whether each of these other temporal asymmetries might fully account for present findings. We have conducted several follow-up studies that collectively demonstrate that the temporal Doppler effect is independent of these other temporal asymmetries. 
One such asymmetry is that, in everyday life, that past has happened and is recalled whereas the future has not happened and must be imagined. Accordingly, it is possible that the asymmetries we observed in the studies using genuine events and times were the result of differences in the type of cognitive processing engaged by the scenarios (i.e., memory in the past conditions but imagination in the future conditions) rather than differences in temporal direction per se. To examine whether the confound between temporal perspective and memory versus imagination might account for the temporal Doppler effect, we conducted a between-persons study in which participants $(N=130)$ imagined being in a hypothetical experiment either one month from now (future condition) or one month ago (past condition). The experiment entailed a “cold pressor" task in which participants submerge their hand in pain-inducing cold water. ${ }^{5}$ Replicating our other findings, participants reported that the cold pressor task was psychologically closer when they imagined it happening one month in the future $(M=4.06, S D=$ 1.29; where 1 = an extremely short time from now; 7 = an extremely long time from now) than one month in the past $(M=4.65, S D=1.31), t(128)=2.56, p=.012, d=0.45$. The temporal asymmetry in psychological distance thus emerged even for a purely hypothetical event, indicating that the future is not psychologically closer than the past simply because the future, unlike the past, has not actually been experienced.

Another temporal asymmetry is that people tend to mentally represent the future more prototypically than the past (Kane, Van Boven, \& McGraw, 2012). On the one hand, this temporal asymmetry in prototypically might suppress the temporal Doppler effect because abstract, prototypical events tend to seem more distant than concrete events (Kyung, Menon, \& Trope, 2010). On the other hand, the temporal asymmetry in prototypically might facilitate the temporal Doppler effect because future, prototypical events are subjectively easier to imagine 
(Kane et al., 2012), and the ease with which people can imagine events reduces their psychological distance (Travers \& Van Boven, 2012; Van Boven, Kane, McGraw, \& Dale, 2010).

To directly examine the effects of abstractness and temporal perspective, we replicated Study $1 b$, crossing temporal perspective with a manipulation in which participants were asked to imagine one year ago [from] today abstractly, as in the original study, or concretely, including details of their location and activities. One year in the future was closer $(M=5.91, S D=2.18)$ than one year in the past $(M=6.69, S D=1.79), F(1,104)=4.18, p=.043$, replicating our other studies, and concretely construed times were closer $(M=5.88, S D=2.02)$ than abstractly construed times $(M=6.68, S D=1.97), F(1,104)=4.36, p=.039$. But there was no interaction between tense and concreteness, $F(1.104)=0.00, p=.983$. This pattern suggests that temporal perspective and representational concreteness independently influence psychological distance.

A final temporal asymmetry is that the lack of specific experiences between the present and the future may cause the interval to be less "filled in" than the equivalent interval between the present and the past. The more easily people can imagine intervening events between the past and the present, the more distantly they perceive the past (Zauberman, Levav, Diehl, \& Bhargave, 2010). To test whether this "filling of the time" (James, 1890/2007, p. 619) might contribute to the temporal Doppler effect, we conducted a new study in which some participants listed a number of tasks they planned to accomplish between the present and a date three weeks in the future. Listing such tasks did not increase the future's psychological distance; rather, it reduced the psychological distance between the present and the future $(M=4.28, S D=1.67)$, relative to a no-listing control group $(M=6.09, S D=2.04), t(55)=3.60, p=.001$.

\section{The Functionality of Facing the Future}


These follow-up studies and the results of Study 3 collectively imply that the temporal Doppler effect is grounded in the metaphorical mapping of spatial and temporal movement, and is not explained by other temporal asymmetries. We believe that the temporal Doppler effect in psychological distance reflects a broad "bias toward the future" whereby people are psychologically oriented toward the future more than the past (Parfit, 1984). This future orientation is highly functional, as future events can typically be acted upon more successfully than past events (Horwich, 1987). As cues representing rewards (money) or threats (guns) become increasingly closer to an individual, they trigger a cascade of processes that include increased emotional arousal and mobilization of the body for action (Löw, Lang, Smith, \& Bradley, 2008). Thus, representing future events as psychologically close may better prepare individuals to approach, avoid, or otherwise cope with future events. For example, psychologically close events tend to arouse more concrete action plans than distant events (Trope \& Liberman, 2010). People who feel close to an upcoming test are more motivated to prepare and to perform well, which manifests in increased practice for the test (Peetz, Wilson, \& Strahan, 2009). In addition, when faced with a looming deadline, people perceive more effortful events to be relatively closer in time, presumably because successful completion of more effortful events requires preparing for them earlier than does successful completion of less effortful ones (JigaBoy, Clark, \& Semin, 2010).

Abetting this functional orientation toward the future, people are also more emotionally oriented to future than to past events (D'Argembeau \& van der Linden, 2004; Van Boven \& Ashworth, 2007), which partially explains why people place higher value on the future than the past (Caruso, Gilbert, \& Wilson, 2008) and why they judge moral transgressions more harshly in prospect than in retrospect (Caruso, 2010). We suspect that one reason why people are more 
emotionally oriented to the future is because the future is psychologically closer than the past. Indeed, a growing body of evidence indicates that mentally increasing psychological distance between the self and significant events substantially reduces people's emotional arousal when contemplating those events (Kross \& Ayduk, 2011).

The fact that action can facilitate the realization of future desires but not past ones may help explain why people devote more resources to prepare for things that lie ahead than for things that lie behind. This is in part why it makes sense for car windshields to be bigger than rearview mirrors and for the meteorologist to discuss the weather for the upcoming week rather than the preceding one. Thus, just as people mobilize resources to prepare for approaching sights and sounds, they apparently have a more general tendency to prepare for the (approaching) future by reducing its psychological distance from the here and now. 


\section{References}

Addis, D. R., Wong, A. T., \& Schacter, D. L. (2007). Remembering the past and imagining the future: Common and distinct neural substrates during event construction and elaboration. Neuropsychologia, 45, 1363-1377.

Boroditsky, L. (2000). Metaphoric structuring: Understanding time through spatial metaphors. Cognition, 75, 1-28.

Boroditsky, L. (2011). How languages construct time. In S. Dehaene \& E. Brannon (Eds.), Space, time and number in the brain: Searching for the foundations of mathematical thought (pp. 333-341). New York: Academic Press.

Boroditsky, L., \& Ramscar, M. (2002). The roles of body and mind in abstract thought. Psychological Science, 13, 185-188.

Buckner, R. L., \& Carroll, D. C. (2007). Self-projection and the brain. TRENDS in Cognitive Science, 11, 49-57.

Caruso, E. M. (2010). When the future feels worse than the past: A temporal inconsistency in moral judgment. Journal of Experimental Psychology: General, 139, 610-624.

Caruso, E. M., Gilbert, D. T., \& Wilson, T. D. (2008). A wrinkle in time: Asymmetric valuation of past and future events. Psychological Science, 19, 796-801.

Casasanto, D., \& Boroditsky, L. (2008). Time in mind: Using space to think about time. Cognition, 106, 579-593.

D’Argembeau, A., \& van der Linden, M. (2004). Phenomenal characteristics associated with projecting oneself back into the past and forward into the future: Influence of valence and temporal distance. Consciousness and Cognition, 13, 844-858. 
Doppler, J. C. (1842). Über das farbige Licht der Doppelsterne und einiger anderer Gestirne des Himmels. In Versuch einer das Bradley'sche aberrations-theorem als integrirrenden Theil in sich schliessenden allgemeineren Theorie [About the colored light of the double stars and of several other stars in the sky: Attempt to create a general theory including the Bradley aberration theorem as an integrated part.] Prague, Czechoslovakia: K. Bohm, Association of Sciences.

Durgin, F. H., \& Li, Z. (2010). Controlled interaction: Strategies for using virtual reality to study perception. Behavior Research Methods, 42, 414-420.

Einstein, A. (1955, March 21). [Letter to Vero Besso \& Bice Rusconi-Besso]. Albert Einstein Archives (7-245.10). Hebrew University of Jerusalem, Jerusalem, Israel.

Freyd, J. J., \& Finke, R. A. (1984). Representational momentum. Journal of Experimental Psychology: Learning, Memory, and Cognition, 10, 126-132.

Frijda, N. H. (1988). The laws of emotion. American Psychologist, 43, 349-358.

Guski, R. (1992). Acoustic tau: An easy analogue to visual tau? Ecological Psychology, 4, 189197.

Horwich, P. (1987). Asymmetries in time: Problems in the philosophy of science. Cambridge, MA: MIT Press.

Hume, D. (1969). A treatise of human nature. London: Penguin. (Original work published in 1739)

James, W. (2007). The principles of psychology (Vol. 1, pp. 605-642). New York: Cosimo. (Original work published 1890)

Jiga-Boy, G. M., Clark, A. E., \& Semin, G. R. (2010). So much to do and so little time: Effort and perceived temporal distance. Psychological Science, 21, 1811-1817. 
Kane, J., Van Boven, L., \& McGraw, A. P. (2012). Prototypical prospection: Future events are more prototypically represented and simulated than past events. European Journal of Social Psychology, 42, 354-362.

Kross, E., \& Ayduk, O. (2011). Making meaning out of negative experiences by self-distancing. Current Directions in Psychological Science, 20, 187-191.

Kyung, E., J., Menon, G., \& Trope, Y. (2010). Reconstruction of things past: Why do some memories feel so close and others so far away? Journal of Experimental Social Psychology, 46, 217-220.

Lakoff, G., \& Johnson, M. (1980). Metaphors we live by. Chicago: University of Chicago Press. Lakoff, G., \& Johnson, M. (1999). Philosophy in the flesh: The embodied mind and its challenge to Western thought. New York: Basic Books.

Lewin, K. (1935). A dynamic theory of personality. New York: McGraw-Hill.

Löw, A., Lang, P. J., Smith, J. C., \& Bradley, M. M. (2008). Both predator and prey: Emotional arousal in threat and reward. Psychological Science, 2008, 865-873.

Mandler, J. M. (1992). How to build a baby II: Conceptual primitives. Psychological Review, 15, 587-604.

Mehlberg, H. (1962). [Review of the book The Direction of Time, by H. Reichenbach]. The Philosophical Review, 71, 99-104.

Miles, L. K., Karpinska, K., Lumsden, J., \& Macrae, C. N. (2010). The meandering mind: Vection and mental time travel. PLoS ONE, 5, e10825. doi:10.1371/journal.pone.0010825.

Miles, L. K., Nind, L. K., \& Macrae, C. N. (2010). Moving through time. Psychological Science, $21,222-223$. 
Neuhoff, J. G. (2001). An adaptive bias in the perception of looming auditory motion. Ecological Psychology, 13, 87-110.

Núñez, R. E., \& Sweetser, E. (2006). With the future behind them: Convergent evidence from Aymara language and gesture in the crosslinguistic comparison of spatial construals of time. Cognitive Science, 30, 401-450.

Parfit, D. (1984). Reasons and persons. New York: Oxford University Press.

Peetz, J., Wilson, A. E., \& Strahan, E. J. (2009). So far away: The role of subjective temporal distance to future goals in motivation and behavior. Social Cognition, 27, 475-495.

Travers, M., \& Van Boven, L. (2012). Ease of imagination reduces psychological distance. Unpublished manuscript, University of Colorado Boulder.

Trope, Y., \& Liberman, N. (2010). Construal level theory of psychological distance. Psychological Review, 117, 440-463.

Van Boven, L., \& Ashworth, L. (2007). Looking forward, looking back: Anticipation is more evocative than retrospection. Journal of Experimental Psychology: General, 136, 289300.

Van Boven, L., Kane, J., McGraw, A. P., \& Dale, J. (2010). Feeling close: Emotional intensity reduces perceived psychological distance. Journal of Personality and Social Psychology, $98,872-885$.

Williams, L. E., \& Bargh, J. A. (2008). Keeping one's distance: The influence of spatial distance cues on affect and evaluation. Psychological Science, 19, 302-308.

Zauberman, G., Levav, J., Diehl, K., \& Bhargave, R. (2010). 1995 feels so close yet so far: The effect of event markers on subjective feelings of elapsed time. Psychological Science, 21, 133-139. 


\section{Acknowledgments}

This research was supported by the Neubauer Family Faculty Fellows program, research funds from The University of Chicago Booth School of Business, and NSF Grants 0552120 and 1049125. We gratefully acknowledge Frank Durgin, Eileen Earl, David Levari, Zhi Li, Valerie Michelman, and Natalie Wheeler for assistance in conducting these experiments, and Barry Schwartz and Peter McGraw for insightful comments on this work. 


\section{Footnotes}

${ }^{1}$ Note that the auditory Doppler effect can also occur through the movement of the source (ambulance), the movement of the target (observer), or both, which is compatible with either the ego movement or time movement metaphor.

${ }^{2}$ See http://www.swarthmore.edu/x33494.xml for a visual demonstration of the participants' experience.

${ }^{3}$ After the distance ratings, participants estimated (in $\mathrm{mph}$ ) how fast they felt they were moving and indicated whether they felt like they were moving through the virtual environment or whether instead they felt like their surroundings were moving past them. There was a marginally significant effect of temporal direction on participants' perceived speed in virtual space $\left(M_{\text {past }}=\right.$ $\left.15.66 \mathrm{mph}, S D_{\text {past }}=9.73 ; M_{\text {future }}=19.89 \mathrm{mph}, S D_{\text {future }}=11.44\right), F(1,76)=3.47, p=.066$. There was, however, no significant main effect of spatial direction or interaction with temporal direction on this measure, both $F \mathrm{~s}<1$, and the interactive effect on psychological distance remained significant after controlling for perceived speed, $F(1,75)=4.30, p=.041$. The majority (89\%) of participants reported feeling that they were moving through the virtual environment as opposed to their surroundings moving past them, and this proportion did not differ between conditions, $\chi^{2}<1$.

${ }^{4}$ Although the perception of movement through time appears to be universal, the specific spatial representations that are used to convey such movement do vary by language and by culture. For instance, the Aymara speak of the past as being ahead of them and the future as being behind them (Núñez \& Sweetser, 2006; for an overview of other differences, see Boroditsky, 2011). 
Future Feels Closer than Past, 22

${ }^{5}$ Four additional participants reported having participated in a "cold pressor" experiment and were removed from analysis. 
Future Feels Closer than Past, 23

\section{Tables}

Table 1. Means (and standard deviations) of psychological distance as a function of temporal direction (Studies 1-2).

Past Future

Study 1a: $\quad 6.52(2.56) \quad 5.22(2.48)$

One Month

Study 1b: $\quad 6.34(2.13) \quad 5.33(2.43)$

One Year

Study 2: $\quad 4.76(1.98) \quad 3.93(1.64)$

Valentine's Day

Table 2. Means (and standard deviations) of psychological distance as a function of temporal direction and spatial direction (Study 3).

Past Future

Forward $\quad 6.06(1.68) \quad 4.78(1.83)$

Movement

Backward $\quad 4.96(2.14) \quad 5.41(1.46)$

Movement 